\title{
AN UNUSUAL FOREIGN BODY IN THE NOSE: DIFFICULTY IN DIAGNOSIS
}

\author{
T. Shankar ${ }^{1}$, B. Kathyayani ${ }^{2}$
}

\section{HOW TO CITE THIS ARTICLE:}

T. Shankar, B. Kathyayani. "An Unusual Foreign Body in the Nose: Difficulty in Diagnosis". Journal of Evolution of Medical and Dental Sciences 2015; Vol. 4, Issue 65, August 13; Page: 11417-11422,

DOI: $10.14260 /$ jemds/2015/1647

ABSTRACT: Foreign bodies in the nose are usually found in children between 2-5years of age, the intellectually impaired and psychiatric patients.(1) When mineral salts are deposited on a long retained foreign body, the object is called a rhinolith. Common objects pushed in to the nose are paper, beads, beans, seeds, nuts and button batteries. Nasal foreign bodies can sometimes be removed in the OPD with a nasal speculum and Hartmann nasal forceps, usually general anesthesia is necessary if the foreign body placed more deeply in the nasal cavity or if a rhinolith has formed. Here we are presenting a case of open safety pin in the (R) nasal cavity with difficulty in diagnosis, removed by endoscopic approach.

KEYWORDS: Aspiration, Airway obstruction, Foreign body, Nasal cavity, Rhinolith.

INTRODUCTION: Foreign bodies in the nasal cavity are commonly encountered in Emergency departments, more frequently seen in the pediatric age group, they can also effect adults, especially with mental retardation or psychiatric illness, children's interests in exploring their bodies make them more prove to lodging foreign bodies in their nasal cavities.(2)

Anatomy of the Nasal Cavity: The nasal cavity extends from the external nares to the choanae, where it becomes continuous with the nasopharynx.

\section{The Nasal Cavity has:}

- Floor.

- Roof.

- Medical wall.

- Lateral wall.

Floor: The floor of the nasal cavity made up of the hard palate.

Roof: The roof is narrow from side to side and is made up of the nasal bones in the upper part and the upper and lower lateral cartilages in the lower part. 


\section{CASE REPORT}

Medial wall: (Fig. No.1) The nasal septum forms the medial wall.

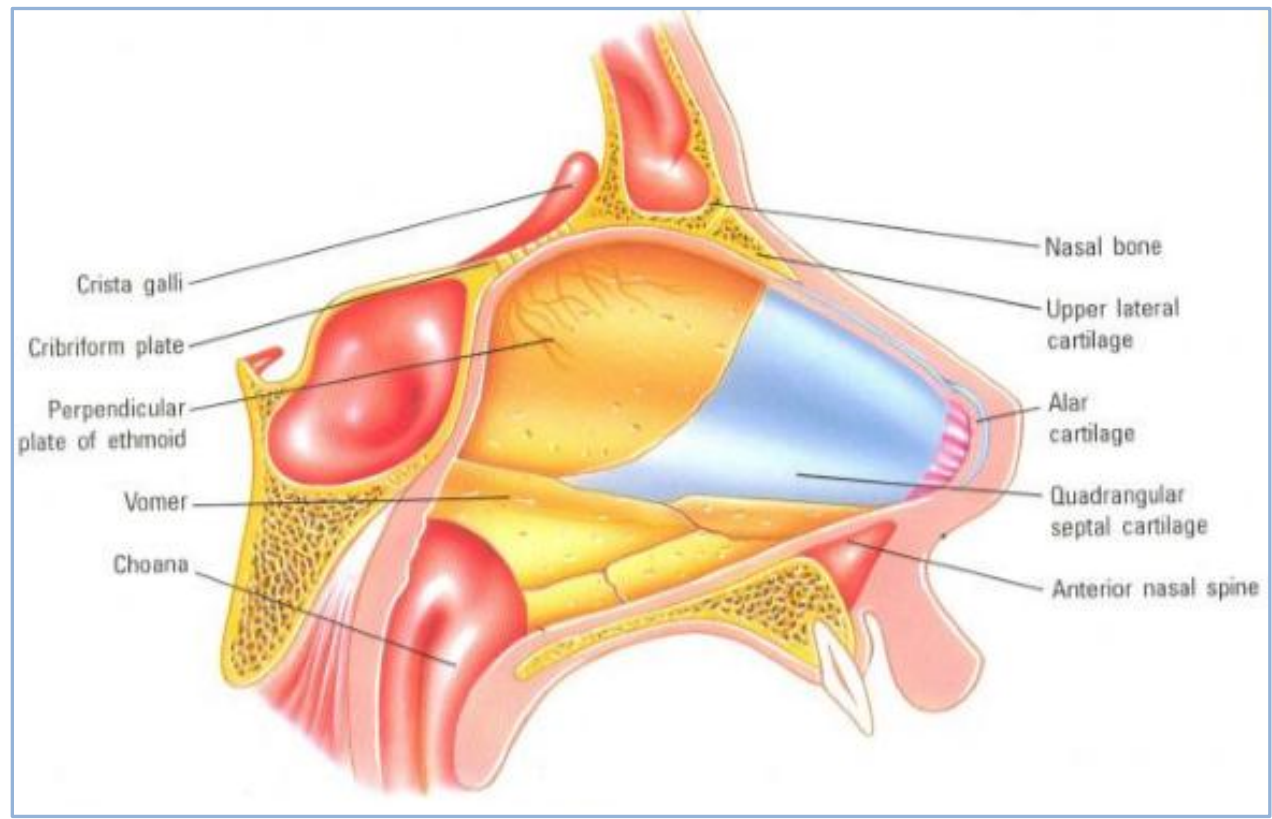

\section{Fig. 1: Nasal Septum}

Lateral wall: (Fig. No.2) The lateral wall of nasal cavity consists of

- 3 Turbinates.

- 3 Meatuses.

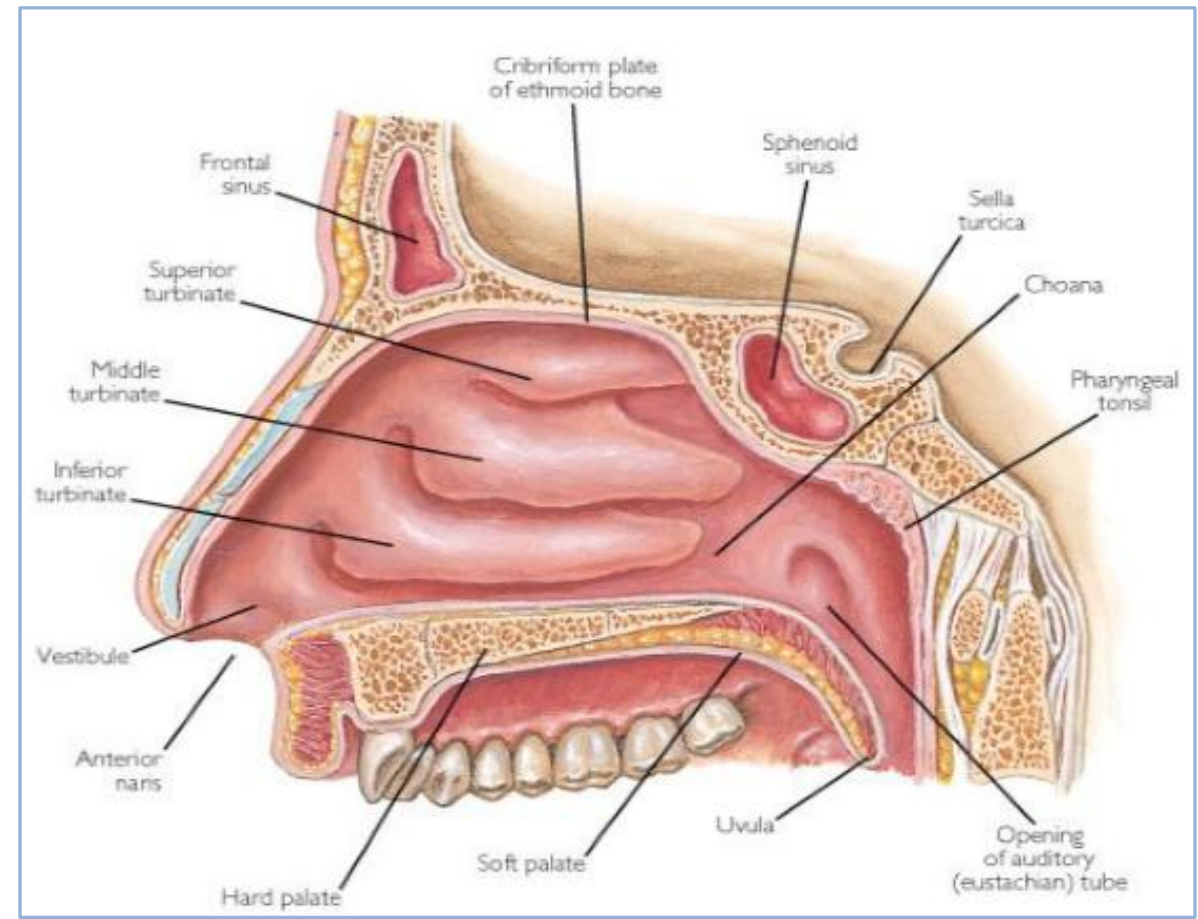

Fig. 2: Anatomy of Lateral wall of the Nose 


\section{CASE REPORT}

\section{Common Types of Foreign bodies in Nose:}

Organic Foreign Bodies: Seeds, Paper, Sponge, Peas etc., they provoke an intense inflammatory reaction from nasal mucosa.

Inorganic Foreign Bodies: Button, Beads, wooden pieces, rubbers, this requires careful removal.

Button Battery: Button Cell battery can cause leakage from battery result in corrosive burns and destruction of the nasal septum, this requires urgent examination under general anaesthesia and removal.

\section{The most common location for Nasal Foreign Bodies is (Fig. No. 3)}

1. Just anterior to the middle turbinate.

2. Below the inferior turbinate.

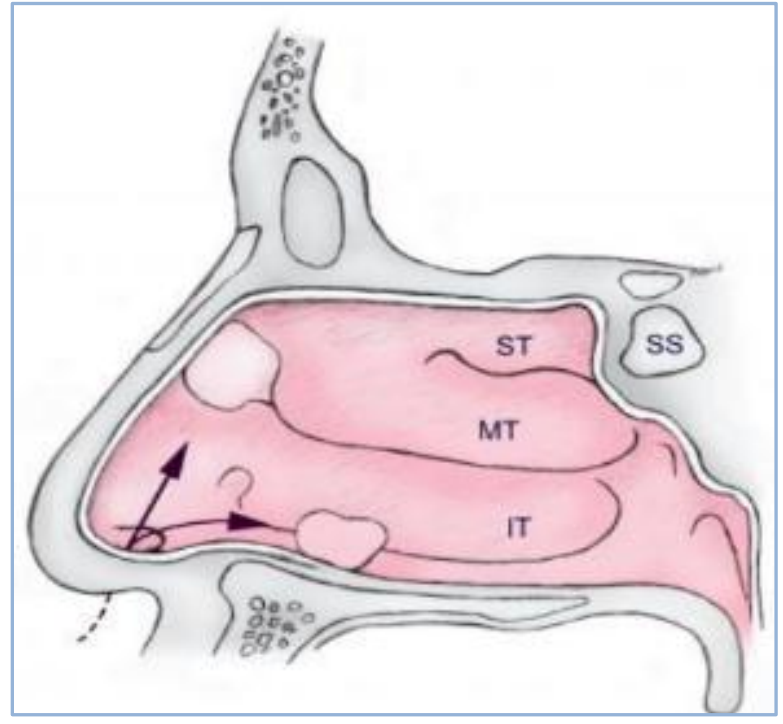

Fig. 3: Common sites of impaction of foreign bodies in the nasal cavity (IT = inferior turbinate; MT = middle Turbinate; SS = sphenoid sinus; ST = superior turbinate)

Unilateral foreign body effect the right nose about twice as often as left nose, this may be due to a preference of right handed individuals for insert objects in to their right nostrils.

\section{Common Symptoms of Foreign Body in Nose.}

\section{A. Early presentation:}

1. Pain in the nose.

2. Excoriation of affected nare.

3. Purulent foul smelling unilateral nasal discharge not responding to medical treatment.

\section{B. Late presentation:}

1. Sinusitis.

2. Unilateral nasal congestion and discharge and nasal obstruction.

3. Rhinolith formation: This is due to deposition of calcium and magnesium salts around the foreign body. 
DIAGNOSIS: Nasal foreign body are usually visible on anterior rhinoscopy, x-ray PNS may revealed foreign body and pan sinusitis, CT scan may demonstrate a radio opaque or impacted foreign body.

\section{Differential diagnosis of foreign body nose:}

1. Polyps.

2. Sinusitis.

3. Tumor.

4. Epistaxis.

5. Unilateral choanal atresia.

TREATMENT: The only treatment for a foreign body in the nose is to remove it from the nostril,(3,4) the foreign body nose can be removed in the OPD with a nasal speculum and Hartmann nasal forceps, in children usually it is removed under general anesthesia by endo tracheal intubation, to avoid pushing a slippery round object deeper, it is better to reach behind the object with a blunt probe and pull it forward. FESS may be required for embedded foreign body.(5)

\section{COMPLICATIONS:}

\section{If Foreign Body not removal:}

- Inflammation in nose \& sinuses.

- Blocks the airway.

- It may inhale the object in to his lungs.

- The object may move in to the sinuses.

- Formation of Rhinolith.

\section{After Foreign Body Removal:}

- Injury to the nasal mucosa.

- Bleeding from the Nose.

As simple as a foreign body nose may see to be, it harbors the potential morbidity due to the mucosal damage and even mortality, if the object is dislodged in to the airway.

CASE REPORT: A 06 year old female child brought to the ENT OPD at Govt. ENT Hospital, Koti, Hyderabad, with chief complaints of (R) side nasal discharge with nasal obstruction since 1 week, no history of epistaxis or pain in the nose.

On Examination: Child is conscious, coherent, on anterior rhinoscopy, mucoid discharge from the (R) Nose, no foreign body seen. Patient admitted for evaluation and removal under general anesthesia all the investigations within normal limits, X-ray PNS shows radio opaque foreign body (safety pin) seen near (R) choanae and nasopharynx, 


\section{CASE REPORT}

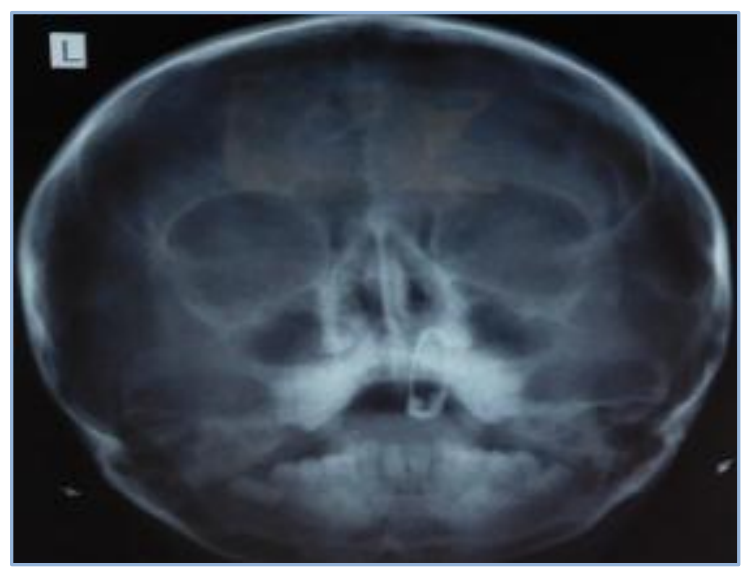

Fig. 4: X-Ray PNS. FB seen in Nasopharynx

Subsequently patient was posted for diagnostic nasal endoscopy and removal of foreign body under general anesthesia. (R) nasal cavity packed with $4 \%$ xylocaine with adrenaline with $0^{0}$ nasal endoscope both nasal cavities are examined, no foreign body seen in either of nasal cavity or nasopharynx, after repeated attempts foreign body could not be seen, than the senior faculty member did DNE (Diagnostic Nasal Endoscopy) after careful examination we could see a purulent thick mucoid plug seen at the anterior end of inferior turbinate, with powerful suction the mucus plug was cleared than we could see a metallic stained foreign body (open safety pin) embedded in inferior meatus, with help of skin hook, the anterior end of foreign body engaged and slowly pulled out. (Fig. No. 5)

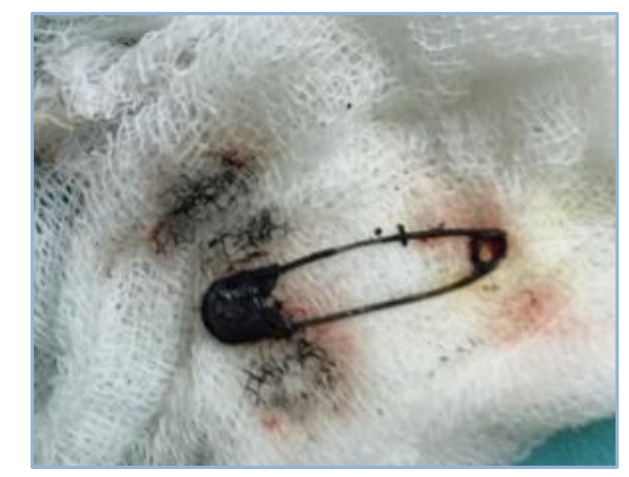

Fig. 5: Foreign Body after Removal

Nasal cavity packed with medicated pack, was removed after 24 hours, post-operative period was uneventful.

CONCLUSION: Nasal foreign bodies (NFB's) are commonly seen in the emergency departments. This is more commonly seen in children, this paper is presented to emphasis the meticulous examination of nose with endoscope, as in this case before we removed the foreign body, another two ENT surgeons have seen and they have declared that there was no foreign body, but after careful DNE procedure we could locate the foreign body and removed safely, hence always search for foreign body in common impaction sites in the lateral wall of nasal cavity, not to depend on radiological report. 


\section{CASE REPORT}

\section{REFERENCES:}

1. Fischer, J. \&Tarabar, A. (2008). Foreign Bodies, Nose. Emedicine.

2. Cameron, P. Jelinek, G. Everitt, I. Browne, G. \&Raftos, J. (2006). Textbook of Paediatric Emergency Medicine. Google Books Preview.

3. Taylor, C. Acheson, J. Coats, T. (2010). Nasal foreign bodies in children: kissing it better. Emergency Medicine journal. PMID: 20581404.

4. Koppuravuri, M. \& Makeham, J. (2010). Parent's kiss to remove nasal foreign bodies in children, Best BETS.

5. Navitsky, R. Beamsley, A. \& McLaughlin, S. (2002). Nasal positive-pressure technique for nasal foreign body removal in children.

\section{AUTHORS:}

1. T. Shankar

2. B. Kathyayani

\section{PARTICULARS OF CONTRIBUTORS:}

1. Professor, Department of ENT, Osmania Medical College, Hyderabad.

2. Senior Resident, Department of ENT, Osmania Medical College, Hyderabad.

FINANCIAL OR OTHER

COMPETING INTERESTS: None

\section{NAME ADDRESS EMAIL ID OF THE}

\section{CORRESPONDING AUTHOR:}

Dr. T. Shankar, Flat No. 201, House No. 12-5-149/6/A, Sajjas Ambeiance, Vijayapura Colony,

Tarnaka, Hyderabad-17.

E-mail: drshankar_ms@yahoo.com

Date of Submission: 21/07/2015.

Date of Peer Review: 22/07/2015.

Date of Acceptance: 05/08/2015.

Date of Publishing: 13/08/2015. 